\title{
SALTO - Study Protocol and Rationale of a Community-Oriented Obesity Prevention Program in the Kindergarten
}

\author{
Susanne Ring-Dimitriou ${ }^{a}$ Thomas Freudenthaler $^{a} \quad$ Verena Aistleitner $^{b}$ \\ Gertrude Horvath $^{a} \quad$ Julia Stallinger ${ }^{a}$ Minas Dimitriou $^{a}$ \\ Elisabeth Ardelt-Gattinger ${ }^{c}$ Daniel Weghuber ${ }^{d}$ \\ a Department of Sports Science and Kinesiology, Paris Lodron University, Salzburg, Austria; \\ bSalzburg Together against Obesity-SALTO, Project Management, Salzburg, Austria; \\ 'Department of Psychology, Paris Lodron University, Salzburg, Austria; d Department of \\ Paediatrics and Obesity Research Unit Salzburg, Paracelsus Medical University, Salzburg, \\ Austria
}

Keywords

Obesity · Prevention $\cdot$ Pre-school $\cdot$ Kindergarten

\begin{abstract}
Background: The prevalence of early childhood overweight and obesity in Austria has reached average European levels of $20 \%$ in boys and $18 \%$ in girls. The rationale and study protocol of SALTO, Salzburg Together against Obesity will be presented, which is aimed to assist adults in increasing the rate of 4- to 6-year-old children with a healthy body weight. Methods: A controlled longitudinal sequential study design consisting of 14 intervention (IK) and 8 control (CK) kindergarten was used to investigate the effect of actions tailored for teachers and parents on BMI among 4- to 6-year-old children. The study launched in November 2014 was approved by the ethics committee of the University of Salzburg. Results: 681 children, 181 parents (119 mothers, 62 fathers) and 30 teachers were investigated until October 2016. Preliminary analyses revealed that more boys (19\%) and fathers (60\% IK, 43\% CK) were overweight and obese than girls (16\%) and mothers (19\% IK, $20 \%$ CK). Conclusion: The challenges faced by the SALTO staff in the implementation of health-promoting actions in the kindergarten are manifold. The Community-Oriented Core Setting (COCS) intervention approach will show whether the actions will reduce the percentage of obesity and be sustainable in the long term.


Ring-Dimitriou et al.: SALTO - Study Protocol and Rationale of a Community-Oriented Obesity Prevention Program in the Kindergarten

\section{Introduction}

Childhood obesity is by no means on the decline $[1,2]$. In fact, a growing body of evidence has shown an increase in the prevalence of overweight and obesity in children below the age of 6 years [3], which has reached 12\% in Romania and even 32\% in Spain [4]. The prevalence rates in Austria are in line with European data: $20 \%$ of boys and 18\% of girls aged 4-6 years are considered overweight and obese by the standards of the World Health Organization [5, 6]. In other words, nearly every 5th Austrian child in this age group has an unhealthy BMI. Numerically this equals one or two children per group of an early childhood education and care service (named 'kindergarten' in Austria). Since overweight and obesity in adolescence persist in adulthood, early prevention strategies are warranted [7-9]. The World Health Organization recently launched the 'Ending Childhood Obesity (ECHO)' campaign to emphasize the importance of interventions that ensure health-enhancing physical activity levels and eating behavior in early childhood $[2,9]$.

Evidence has shown that obesity prevention programs in schools have minimal effects on a few obesity inducing components, but no impact on the prevalence of obesity [10-12]. In contrast, prevention strategies targeting the community seem to be beneficial in reducing the prevalence of obesity over time, as shown in obesity prevention programs using the EPODE methodology [13-15]. However, the sustainability of interventions targeting eating habits and sedentary lifestyles are questioned because they do not translate into actions in the daily lives of the target population $[16,17]$. Hence the implementation of health-enhancing actions at the kindergarten level is crucial for the prevention of obesity.

Concepts like Tigerkids in Germany [18, 19], ToyBox in Europe [20,21], or Munch and Move [22] in Australia focus on the feasibility of implementing actions by providing educational material that is acceptable to kindergarten teachers. All three initiatives offered a workshop once a year, a hotline, and educational material (manuals, tip cards) to assist kindergarten teachers in implementing the actions over the 20- to 24-month program [18, 22, 23]. Parents were given web-based (homepage, newsletter) and paper-based (tip cards) educational information to facilitate the implementation of health-enhancing actions in the family setting $[18,22,24,25]$. The programs were found to exert a positive effect on eating behavior [18, 22] and/or motor skills [20,22].

Although it was believed that improving health literacy, i.e. the individual's cognitive, behavioral and societal skills, would facilitate the implementation process; this aspect was given little attention in prevention programs [26]. Currently, programs for the prevention of early childhood obesity provide no data on changes in the skills of kindergarten teachers and parents in the implementation of health-enhancing actions in the kindergarten. As suggested recently, prevention strategies focusing on a setting nested within a community appear to be more promising in terms of the integration of actions into the individual's daily life [27].

The Community-Oriented Core Setting (COCS) approach is encouraging because it relies on a socio-political framework that helps to identify barriers and facilitators for tailoring and implementing sustainable actions. For instance, in Austria all preschoolers (5-6 years of age) are obliged to attend kindergarten as a preparation for primary school. To fulfil the requirement of equal access to education, a second compulsory year ( $4-5$ years) is currently being discussed at the ministerial level [28]. Furthermore, a 'health-in-all-policies strategy' with special focus on health promotion in early childhood has been implemented in the last few years in order to ensure the healthy growth of children and adolescents and to promote health-enhancing and safe physical activities in daily life [29-32]. In view of the need for obesity prevention in early childhood [33] as well as the role of the kindergarten as a core unit of the community and a healthy lifestyle in the family $[13,20]$, we developed the initiative SALTO - SALzburg Together against Obesity - which was launched in November 2014. 
Ring-Dimitriou et al.: SALTO - Study Protocol and Rationale of a Community-Oriented Obesity Prevention Program in the Kindergarten

The overall aim of the 3-year study is to increase the proportion of preschoolers with a healthy body weight when they enter school, i.e. at the age of 6 years, by a program focusing on the health literacy of kindergarten teachers and parents with a view to implementing suitable and sustainable health-enhancing practices [26]. We also intend to influence the health concepts of kindergarten teachers and parents with reference to obesity, physical fitness (improving fundamental motion skills), physical activity behavior (reducing sedentary behavior in various contexts), nutrition (drinking more water, consuming vegetables and fruit) and eating behavior (child-friendly portion sizes of food). Finally, we intend to aim incorporate obesity prevention in early childhood into the curriculum of the education system of kindergarten teachers. The study rationale and protocol is described in the following.

\section{Rationale}

The COCS intervention approach in which the kindergarten serves as a core unit of community-based prevention of early childhood obesity gave rise to the socio-ecological model of health promotion which was used for SALTO initiative [34-38]. Accordingly all actions implemented in SALTO were based on the following:

- The national framework: the concept of health incorporated in the policies and recommendations of the Ministries of Health, Education and Sports regarding the care and education of 4- to 6-year-old children [28, 30, 31];

- The organizational framework: the funding bodies of the kindergarten, the education levels of kindergarten teachers, legal authorities, the opening hours of services, and the structural frameworks of the kindergarten, such as the built environment as well as indoor and outdoor areas [29];

- The individual framework: focusing on the healthy growth of young children $[11,18$, $39,40]$.

We identified the interpersonal level as the key layer for SALTO actions because kindergarten teachers and parents are the key drivers of health promotion in children (fig. 1). The simple fact that children grow up in the world of adults means that adults are able to facilitate or impede the adoption of a healthy lifestyle by the child [11, 18, 20, 41]. To facilitate changes in health behavior, we utilize concepts targeting the cognition of exercising and eating as well as competences in implementing health-oriented actions into the kindergarten, e.g., the stages of change [42,43], the sense of coherence [44], health beliefs [45-47], social learning [48] and self-determination $[49,50]$.

Moreover, the actions of teachers in the kindergarten are the result of a legal framework at the national and municipal level (community environment), and the individual needs of the child (personal environment). Accordingly, the level of health literacy and the competences of kindergarten teachers and parents in implementing health-enhancing actions are crucial and serve as mediators in the model as suggested by Fuchs $\left(\mathrm{ES}_{\mathrm{A} \rightarrow \mathrm{M}}\right)$ [43]. It is assumed that the mediators differ in the magnitude of their impact on health behavior changes in children $\left(\beta_{\mathrm{M} \rightarrow \mathrm{HB}}\right)$. In other words, how effectively a health-behavior change in children can be induced by actions in the kindergarten $\left(\mathrm{ES}_{\mathrm{A} \rightarrow \mathrm{HB}}\right)$ depends on tailoring actions that address the principal mediators, such as the health literacy and skills of teachers and parents $\left(\mathrm{ES}_{\mathrm{A} \rightarrow \mathrm{HB}}=\right.$ $\mathrm{ES}_{\mathrm{A} \rightarrow \mathrm{M}}{ }^{*} \beta_{\mathrm{M} \rightarrow \mathrm{HB}}$; see fig. 1).

Furthermore, reducing or stabilizing the prevalence of early childhood obesity needs the development of evidence-based, effective, low-cost, feasible, and sustainable actions. Tailoring, implementing, evaluating, and scaling-up such actions require a process approach consisting of a project initiation phase (the development, adoption, and evaluation of actions suited to the target groups and setting), a program phase (the implementation and evaluation 
Fig. 1. SALTO model of childhood obesity prevention in the kindergarten, where the effect size (ES) of actions on health behavior is a function of the effect size of the action on the relevant mediators and the role (weight) the mediators play in health behavior change [41].
Ring-Dimitriou et al.: SALTO - Study Protocol and Rationale of a Community-Oriented Obesity Prevention Program in the Kindergarten

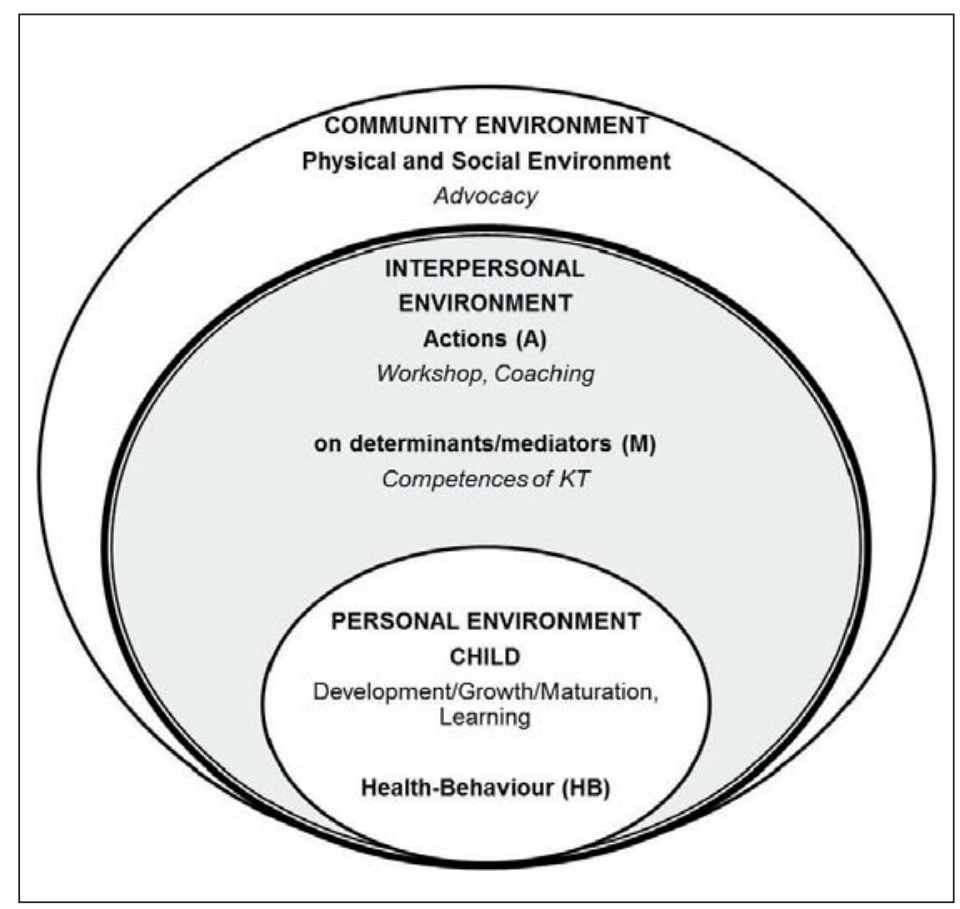

of the most successful actions of the project phase), and a scaling-up phase (sustainable actions that become part of policies and are adopted in many communities) [27]. For this process approach, we rely on the health-action cycle $[27,51,52]$ as well as on the framework for developing and evaluating complex interventions $[53,54]$.

\section{Material and Methods}

In the following, methods used to implement and evaluate the effects of actions in the project initiation phase will be described. SALTO relies on the EPODE method and is based on a multiple-method, multisectoral and multi-stakeholder approach [13]. The project is conducted under the patronage of the Federal State Minister of Education, Sports, Migration and Science, and was launched in November 2014 in Salzburg, Austria.

\section{Study Design and Sample}

SALTO is a longitudinal-sequential trial consisting of intervention (IK) and control kindergartens (CK). All participating children, parents and kindergarten teachers of both groups (IK, CK) will be investigated in regard of sociodemographic data, physical activity behavior and preferences, eating behavior and nutrition preferences, and physical fitness levels on a yearly basis. Thus, cross-sectional and longitudinal (birth cohorts 2012 and 2011) samples (fig. 2) will be investigated.

In $2014 / 2015,17,735$ children $(3,568$ in the city of Salzburg, 14,167 in the federal state of Salzburg) aged 3-6 years were registered in early child education services (state of Salzburg, 2015) in 119 communities (545,818 inhabitants, $27.6 \%)$. Early childhood education services operate as institutions affiliated to the municipality or the the church, or function as a private organization (such as forest kindergarten or sports kindergarten).

A kindergarten is included in SALTO when the entire kindergarten team (the head, teachers, and assistants) is willing to complete the SALTO actions over a period of 2-3 years. Thus, the kindergartens could not be randomized to the intervention or the control arm. We recruited kindergartens from the city of Salzburg and the five federal districts of Salzburg with the aid of the civil services, and allocated the kindergartens regionally (district) to the IK or the CK. From November 2014 to January 2017, at the district level all kinder- 
Ring-Dimitriou et al.: SALTO - Study Protocol and Rationale of a Community-Oriented Obesity Prevention Program in the Kindergarten

\begin{tabular}{|c|c|c|c|c|c|c|}
\hline $\begin{array}{l}\text { Birth- } \\
\text { cohort }\end{array}$ & $\begin{array}{l}\text { Age- } \\
\text { group }\end{array}$ & & & & & \multirow{5}{*}{ Mini-Longitudinal } \\
\hline \multirow{4}{*}{$\begin{array}{l}2012 \\
2011 \\
2010 \\
2009\end{array}$} & \multirow{4}{*}{$\begin{array}{c}\text { 3-4 y. } \\
\text { 4-5 y. } \\
\text { 5-6 y. } \\
6 y .\end{array}$} & 3.5 & 4.5 & 5.5 & \multirow[t]{4}{*}{6} & \\
\hline & & 4.5 & 5.5 & 6 & & \\
\hline & & 5.5 & 6 & & & \\
\hline & & 6 & & & & \\
\hline & & $\begin{array}{l}\text { T1: } \\
\text { Mar, } \\
\text { Oct, } \\
2015\end{array}$ & $\begin{array}{c}\text { T2: } \\
\text { Mar, } \\
\text { Oct, } \\
2016\end{array}$ & $\begin{array}{c}\text { T3: } \\
\text { Mar, } \\
\text { Oct, } \\
2017\end{array}$ & $\begin{array}{l}\text { T4: } \\
\text { Mar, } \\
2018\end{array}$ & \\
\hline & & $\begin{array}{l}\text { Mini- } \\
\text { Cross- } \\
\text { sectional }\end{array}$ & & & $\begin{array}{c}\text { 3-y. } \\
\text { Pre- } \\
\text { valence }\end{array}$ & \\
\hline
\end{tabular}

Fig. 2. Mixed-longitudinal design to explore overweight and obesity at 6 years of age, as well as the development of motor skills and behavior change in preschoolers.

gartens $(\mathrm{n}=350)$ were informed about the aims of the project several times by mail, by the federal departments, and by SALTO. On a specific day in February 2015, all 34 kindergartens of the city were informed about the project by a civil servant of the city department and by SALTO. 14 IK and $8 \mathrm{CK}$ were recruited from the five districts and the city of Salzburg.

Data were collected from the study participants (caregivers and children), and informed consent was obtained in writing from the legal guardians of all children (mother/father, both) and from the participating adults (kindergarten teachers and parents). The study design was approved by the ethics committee of the University of Salzburg (EK-GZ 25).

\section{Staff and Project Development}

In the project initiation phase, the SALTO actions are planned and implemented by the project team (PLT). The latter consists of a director (in charge of the overall concept, personnel, budget, evaluation, and dissemination), a medical director (in charge of medical affairs, and childhood obesity), a project manager (in charge of project implementation, strategy, budget controlling, and communication), a kindergarten coordinator (in charge of implementing actions based on half-year schedules and in charge of communication between the PLT and the kindergarten), and a test coordinator (in charge of scientific evaluation).

The PLT meets on a bi-weekly basis (for $1.5 \mathrm{~h}$ ) and on demand. Strategy meetings are organized with medical experts on a quarterly basis, and a stakeholder dialogue takes place once a year. The PLT participates once a year in the EPODE obesity forum to improve the overall planning, design, implementation, and evaluation of actions. The PLT is supported by scientific staff including sports scientists, psychologists, and nutritionists. These assist in testing and in conducting workshops and coaching sessions on health literacy concerning obesity prevention. Cooperation is maintained with external providers such as sports organizations, private companies, or community services in order to implement the actions regionally.

The procedural development of the concept and actions is supported by an expert club consisting of former kindergarten teachers, college teachers of preschool education, educationalists focused on elementary schools, psychologists, sociologists, and political stakeholders. The club meets twice a year. Furthermore, a meeting for all participating kindergarten teachers is held once a year to discuss barriers and facilitators of implementation. Regular meetings with politicians are organized at the community and national level in order to communicate the achievements of the kindergartens. 
Ring-Dimitriou et al.: SALTO - Study Protocol and Rationale of a Community-Oriented Obesity Prevention Program in the Kindergarten

Table 1. Sequence and list of SALTO actions for kindergarten teachers, parents, stakeholders and the public

\begin{tabular}{|c|c|c|}
\hline Module & Type of actions & Function in the project initiation phase \\
\hline \multirow[t]{6}{*}{$\begin{array}{l}\text { Kindergarten } \\
\text { teacher }\end{array}$} & 1. Situation analysis (knowledge) & $\begin{array}{l}\text { SALTO performs an on-site analysis by conducting interviews with } \\
\text { kindergarten teachers, taking pictures and determining their knowledge } \\
\text { on SALTO topics. } 1 \times\end{array}$ \\
\hline & 2. Workshop (persuasion) & $\begin{array}{l}\text { Part I: Reshaping the individuals' cognitions of obesity, healthy eating, } \\
\text { and exercising; Part II: Utilizing the mPAST-method (modified problem } \\
\text { solving tree, WHO) to determine the sequence of SALTO topics } \\
\text { (intervention mapping): 1. Determining urgent topics, } 2 \text {. Identifying } \\
\text { barriers and facilitators in regard of SALTO topics, 3. Rating the } \\
\text { feasibility and priority of actions; } 4 \text {. Determining actions for the first } \\
\text { topic while developing the first half-year schedule. } 1 \times\end{array}$ \\
\hline & 3. Half-year schedule (decision) & $\begin{array}{l}\text { The SALTO coordinator visits the kindergarten every } 6 \text { months, decides } \\
\text { and discusses the half-year schedule and actions. Based on reflection and } \\
\text { feedback, the actions are tailored to the respective needs. } 6 \times\end{array}$ \\
\hline & 4. Coaching (skill training) & $\begin{array}{l}\text { The following topics will be addressed at least once per project period: } \\
\text { How to communicate with parents? How to assist children and ensure } \\
\text { their safety during exercises? How to implement circus exercises to } \\
\text { improve motor skills? } 3 \times\end{array}$ \\
\hline & $\begin{array}{l}\text { Didactic material by SALTO \& } \\
\text { co-creation }\end{array}$ & $\begin{array}{l}\text { Written material such as manuals (A4) and booklets (A5) concerning } \\
\text { 'motion', 'nutrition' and 'media' are provided to all kindergarten } \\
\text { teachers, summarizing the SALTO approach. Co-creation: Christmas } \\
\text { calendar showing } 24 \text { physical exercises developed by SALTO, based on } \\
\text { the ideas of a kindergarten teacher. SALTO poster for each kindergarten, } \\
\text { SALTO half-year process schedule. 1× }\end{array}$ \\
\hline & Certificate & $\begin{array}{l}\text { A certificate will be issued at the end of the project when the following } \\
\text { actions have been completed: } 1 \text { workshop, } 2 \text { coaching sessions, } 1 \\
\text { participation in the exchange meeting, } 1 \text { SALTO parent's day/year, } \\
\text { annual testing. } 1 \times\end{array}$ \\
\hline
\end{tabular}

Parents 1. Parents evening (persuasion)

Introducing SALTO: Together with the KT the SALTO coordinator and project manager will explain the aim and testing procedures of SALTO with the aid of a video film. Preliminary tips and recommendations for healthy exercise and eating at the family level will be provided; Nomination of a SALTO peer, i.e. a parent who communicates parental issues to SALTO and the kindergarten, and vice versa. $1 \times$ Educational presentation of SALTO topics and identification of immediate barriers to the implementation of SALTO topics. $1 \times$ The coordinator meets parents in the kindergarten for an exchange regarding barriers/facilitators in implementing SALTO actions in the family setting. $6 \times$

\section{SALTO box (skill training)}

Based on special needs, actions are implemented in co-creation, such as the climbing box to promote climbing skills of children and parents, under the supervision of a guide; the bread-baking box to show children how to bake bread, provided by a farmer. $2 \times$

Didactic material by SALTO

Take-home activities, Newsletter

SALTO provides take-home activities to parents and children, such as
Written material in the form of illustrated and colored cards for all six topics; the cards can be hung visibly and viewed by all family members at home. $1 \mathrm{x}$ finding the best playground for climbing, via a monthly e-mail newsletter or through the child. $36 \times$ 
Ring-Dimitriou et al.: SALTO - Study Protocol and Rationale of a Community-Oriented Obesity Prevention Program in the Kindergarten

Table 1. Continued

\begin{tabular}{lll}
\hline Module & Type of actions & Function in the project initiation phase \\
\hline Stakeholder & Expert club & $\begin{array}{l}\text { Exchange with experts to improve and select actions that can be implemented in } \\
\text { the kindergarten and the education system by college teachers. } 5 \times\end{array}$ \\
& Exchange with regional stakeholders and kindergarten teachers to communicate \\
& the aims of SALTO. 3× \\
& A quarterly newsletter for stakeholders, with information and tips on relevant \\
& SALTO topics. $12 \times$
\end{tabular}

\section{Intervention Framework}

Actions are tailored to suit the annual curriculum of each intervention kindergarten and are based on a multifactorial evidence-based approach developed from previous initiatives [13, 16, 18, 21, 22]. We target six health topics. Three address eating: portion size and vegetables, water consumption and nutrients for children, sweets/snacks and special situations; and three address physical activity: sitting/standing and outdoor activities, fundamental motion skills and family leisure time activities, screen time and sports activities. Each topic will be translated into various actions of 6-month duration, applied consecutively to foster implementation. This strategy acknowledges the fact that it is easier to change an individual's behavioral attitude and associated behavior by various channels (such as kindergarten teachers, parents, social media) rather than all relevant health behaviors simultaneously, such as reducing sedentary times, increasing water consumption, and increasing the duration of outdoor activities [43]. The order of topics was selected by the kindergarten teacher team in the workshop utilizing the modified problem solving tree method (mPAST) and every half-year iteratively (see also text in table 1). This approach is supported by recent data from the ToyBox study, underlining the importance of the degree of implementation [55].

The actions for implementing the six health topics are clustered into four modules targeting kindergarten teachers, parents, stakeholders, and the public to promote the termination of childhood obesity. The functions of each action are listed in table 1. To improve test attendance rates, control groups receive incentives such as a day at the zoo or a sports device as a toy for each child (a 'fun ball').

\section{Evaluation Framework and Testing Procedures}

All participants (children, parents and teachers) who have given their written informed consent will be measured on a yearly basis (October or March, 2014-2018) in regard of various indicators. The main outcome is the change in the percentage of overweight and obesity in 6-year-old children, measured as the standardized body mass index (SBMI) as recommended by the WHO [2, 5]. Secondary outcomes are changes in the nutrition and physical activity preferences of adults, the activity behavior of adults and children, the body image of adults, and levels of fundamental movement skills in children.

In order to maintain the cycle from evidence-based practice to practice-based evidence, we developed a concept of evaluation based on the recommendations of Bauman and Nutbeam (2014) [56] and the World Health Organization (2011) [56]. The evaluation targets the project initiation phase of the project, in terms of a formative evaluation consisting of input indicators to define the problem and generate the solution, and the evaluation of the feasibility of actions based on input indicators such as the education level of the project team, experiences in coaching as well as output indicators such as the number of completed actions and the type of actions in the kindergarten. The effectiveness of SALTO actions is being evaluated on a cross-sectional basis as well as longitudinally (fig. 2) by changes in outcome indicators such as anthropometric data (BMI, 
Ring-Dimitriou et al.: SALTO - Study Protocol and Rationale of a Community-Oriented Obesity Prevention Program in the Kindergarten

waist circumference), physical activity and nutrition preferences, and the level of fundamental movement skills. The outcome indicators are collected by an educated staff consisting of a test coordinator, two sports scientists, and two psychologists. All testers (collectors) completed two standardized 4-hour training courses consisting of a theory section that includes an explanation of the standard operating testing protocols based on written and video material, and a practical course. All testers receive a written tester manual before completing the tests in the kindergarten (SALTO Manual, Freudenthaler and Ring-Dimitriou, unpublished manual) [57].

The following measures were taken to limit the risk of bias on treatment effects:

- The educator is an expert in motor testing and educates the testers based on the written tester manual.

- The collectors are separated from the evaluators; the former are not involved in data processing and

analysis.

The following measures were taken to limit the risk of attrition:

- face-to-face visits by the SALTO coordinator as a core strategy,

- a hotline for kindergarten teachers and parents to assist them in their implementation of the actions,

- the delivery of all educational materials and actions at no cost during the project initiation phase,

- non-monetary incentives to the control kindergarten,

- $\quad$ an intention-to-treat design for testing all baseline participants (children, parents, kindergarten

teacher) at the end of the project phase, and

- checking the flow of study participants twice a year.

\section{Anthropometrics}

The following tests are performed in 3- to 6-year old children: anthropometric measures such as body mass $(\mathrm{kg})$ with a standardized balance scale, and body height $(\mathrm{cm})$ with a stadiometer (seca, Hamburg, Germany), in light clothing and barefoot. The BMI as a ratio of body mass ( $\mathrm{kg})$ to body height $\left(\mathrm{m}^{2}\right)$ is standardized (SBMI) to sex and age by using the web-based tool PC PAL WebCalc Version 2.0 (2016-07-15, pcpalsoftware.eu). The percentage of overweight and obese children is calculated [2,5]. Waist circumference $(\mathrm{cm})$ is measured with a recently validated belt for children with a re-test reliability of $r_{S}=0.97$ and a good test agreement $\left(r^{2}=0.94\right.$, systematic difference of $0.5 \mathrm{~cm}$ ) compared to a standard procedure (tape) [58].

\section{Fundamental Movement Skills}

Fundamental movement skills are measured as a process (scores, MOT1) or a product (cm, s; MOT2) outcome, in which changes in the motor components of postural control (one-leg stance, balance), object manipulation (catching, throwing, kicking a ball) and locomotion (running, single-lateral and lateral jumping, standing broad jump, shuttle run, roll forward) are investigated $[59,60]$. The validation of the test battery (multi-trait multi-method approach) is under investigation, and re-test reliability of single tests is high with $r>0.80$.

\section{Socio-Psychological and Demographic Items}

Both, parents and the respective kindergarten teacher receive a paper version of the self-administered SALTO questionnaire. The instrument includes cognitional, behavioral and societal items such as physical activity preferences, nutrition preferences, media consumption (self-report, proxy report for one's own child), body image, and sociodemographic data such as marital and migration status. The questionnaires are sent by mail to each kindergarten group and handed out to the parents by the kindergarten teacher. Filled and sealed questionnaires are collected by the kindergarten teachers and the SALTO coordinator. The questionnaires are analyzed by the principal investigators (project director and test coordinator). Physical activity and nutrition preferences in children are tested directly with new developed visual tests (consistency, Cronbach's alpha $=0.81$ and 0.81 , re-test reliability $r_{s}=0.41-0.63$ and $0.12-0.68$ ), where children rate between 'I like that a lot', 'I like it', 'I don't like it at all' [61, 62].

\section{Feasibility of the Program and Literacy}

With the aid of external evaluation, the feasibility of SALTO actions in the daily routine of the kindergarten were and will be investigated qualitatively in 2016 and 2017 by group and face-to-face interviews (Salzburg University of Applied Sciences, Maislinger-Parzer, unpublished data) [63]. 
Ring-Dimitriou et al.: SALTO - Study Protocol and Rationale of a Community-Oriented Obesity Prevention Program in the Kindergarten

\section{Statistical Analysis}

In accordance with the mixed-longitudinal design, all data are analyzed descriptively and analytically. The annual report includes a frequency analysis of various outcomes concerning moderators (independent variables) such as age groups, sex, and the kindergarten groups. An interim inference analysis will not be performed before all data have been collected in order to avoid testing or intervention 'to the result'. After the fourth time point of data collection, linear and generalized mixed model analyses will be performed to determine mean differences in repeated measures (within factor $=$ time) among children, parents, and kindergarten teachers. Mixed models will be used to test for mean differences in various outcomes of children, parents, and kindergarten teachers between IK and CK (between factor = group). The effect of SALTO on the percentage of obese persons and the motor skills of children (dependent variables, outcomes) will be further examined by mediators of change such as nutrition and physical activity preferences or anthropometric (e.g. self-reported BMI) and sociodemographic (e.g. marital and migration status) data of parents (independent intervention variables) by regression models (moderator-mediator/path analysis).

\section{Preliminary Results}

We report descriptively the preliminary data of the SALTO study. Of 384 facilities, 22 (14 IK, $8 \mathrm{CK}$ ) were involved in the project initiation phase which extended from March 2015 to October 2016. 681 children (IK $4.6 \pm 0.9$ years, CK $4.7 \pm 0.9$ years) were tested for fundamental movement skills and 503 for BMI (49.5\% girls); 181 parents (119 mothers, $34.3 \pm 6.0$ years; 62 fathers, $37.5 \pm 6.5$ years) and 30 kindergarten teachers ( 1 male) filled in the questionnaire.

The baseline data indicate a higher overweight and obesity percentage in boys $20 \%$ in IK and 18\% in CK; overweight/obesity: IK $=90,14 \% / 6 \%, \mathrm{CK}=60,12 \% / 7 \%$ ) than in girls (16\% in IK and in CK; IK = 95, 13\%/3\%; CK = 49, 12\%/4\%). With regard to the parents' selfreported body mass and height, a significantly higher rate of overweight and obesity was noted in fathers (IK 60\%, CK 43\%) than in mothers (IK 20\%, CK 19\%). More mothers than fathers had a university education (24\% vs. $16 \%$ ), whereas more than $95 \%$ of fathers compared to $12 \%$ of mothers - had a full-time job. Only $8 \%$ of the parents have a migration background. The data of kindergarten teachers are currently under investigation.

The first external evaluation, completed as an interview of kindergarten teachers during an exchange meeting, revealed the following (unpublished report of Urstein Research, Maislinger-Parzer and Grössenberger, 2016) [63]:

- The interviewed persons would like SALTO to follow the motto of 'Less (action) is more .... SALTO must be adapted to our kindergarten .... Parents should be involved to a greater extent in the kindergarten.'

- Project barriers such as 'changing beliefs about obesity, eating, and exercising is hard work and needs time', and

- Project facilitators/success indicators such as 'The educational materials of SALTO are very helpful, a wide range of actions is welcome, and the SALTO coordinator's support in the implementation process is essential and very welcome.'

\section{Discussion}

We present the study protocol and rationale of the project initiation phase of SALTO. The 36-month prevention program will be conducted in the kindergarten setting with the aim of reducing overweight and obesity in 6-year-old children. Four modules were created, each with actions targeting the cognition and competences of kindergarten teachers, parents, stakeholders, and the public, to foster health-enhancing behavior in preschool children. 
In accordance with recommendations concerning complex interventions and the results of promising obesity prevention programs, we implemented actions relating to the six health aspects of physical activity (sitting/standing and outdoor activities, fundamental motion skills \& family leisure time activities, screen time and sports activities), and eating behavior (portion size and vegetables, water consumption and nutrients for children, sweets/snacks \& special situations) in cooperation with the kindergarten team $[13,18,22$, $24,53]$.

Although we follow the community-based EPODE method, the COCS approach was considered a crucial aspect of SALTO in order to integrate evidence-based and sustainable actions into the core setting, alongside regional and national health policies [55]. Accordingly, we developed our didactic manuals with experts in the field. The educational material facilitated the implementation of SALTO actions, as noted by others as well [18, 22, 64, 67].

In contrast to other programs, we focused on the regulation of cognition and competences concerning knowledge about the health behavior of kindergarten teachers and parents in order to ensure behavior changes in children. Intensive actions were undertaken in this regard. In addition to didactic materials, workshops and a hotline, we provide coaching lessons and social media activities over the long project initiation phase. This was done to support the implementation process and create sustainable actions [18, 20, 22]. The kindergarten teachers mentioned this aspect at the external evaluation interview. They reported that the cognitive process activated in the workshop was exhausting. Hence we created an acquaintance workshop $(1 \times 2.5 \mathrm{~h})$ for explaining the rationale and aim of the project, and then started the action sequence listed in table 1 . A long initiation process was crucial for creating and implementing sustainable actions in the kindergarten, as endorsed by other authors $[17,20,27]$.

The preliminary data of SALTO revealed the urgency of obesity prevention in early childhood: $19 \%$ of boys and $16 \%$ of girls aged 4-6 years were overweight and obese, which is in line with the overall data for Austria [6]. Interestingly, SALTO mothers are slimmer than average Austrian women (30\% overweight and obese), whereas SALTO fathers conformed to the Austrian average of every second adult male being overweight or obese [65]. As the body weight of parents is associated with the development of childhood obesity, adult mediators deserve greater attention in intervention programs and were also the keynote of our actions of the parent's module [8, 66, 67].

The challenges faced by the SALTO project team in the development and implementation of actions include the heterogeneous conditions of kindergartens concerning the funding body (public, private, companies), the level of professionalism of kindergarten teachers (non-academic, public or private education, the differing duration of education: 2 , 3,4 or 5 years, different levels of advanced education courses), the educational concepts of kindergartens (classic elementary school pedagogy; Waldorf, Montessori, Reggio; forest kindergarten, sports kindergarten), and governmental jurisdiction (national level: providing a general framework of the education concept; federal state level: defines the opening hours, salaries, personnel, infrastructure, and monitoring/advocacy of educational concepts).

We are aware of these challenges, which will be considered when re-formulating the aims of SALTO. These will be used to select feasible and sustainable actions for the next stage in the scaling-up cycle, when the project will be transformed into a program for the prevention of obesity in early childhood [27]. If shown to be efficacious, the SALTO method will influence educational concepts, the education system and regional policies, and will affect health behavior at the interpersonal level in the kindergarten setting. 
Ring-Dimitriou et al.: SALTO - Study Protocol and Rationale of a Community-Oriented Obesity Prevention Program in the Kindergarten

\section{Acknowledgments}

The study protocol presented here is a part of the research pillar of the SALTO project (www.saltosalzburg.at) under the patronage of the Federal Minister of Education, Sports, Migration and Science of the State of Salzburg. We gratefully acknowledge the financial support of the Austrian Ministry of Defense and Sports, the Health Fund of the Federal State of Salzburg, and private partners who funded the actions. A special thanks to the supporting legal authorities of the state kindergarten services, the external public, private partners in sports and agriculture, the EPODE consortium, the participating kindergarten teachers, parents, and children.

\section{Disclosure Statement}

The authors declare no conflict of interest. We declare that i) no personal funding was provided to any author; ii) no spouses, partners, or children have financial relationships that may be relevant to the submitted work; iii) no authors have non-financial interests that may be relevant to the submitted work. The funding sources of SALTO did not influence the study design, completion, and interpretation of results as well as writing of the manuscript. All funding partners gave their informed and signed consent to the ethical code of SALTO, indicating no branding of the project or interference in the study design (www.salto-salzburg.at/files) kombiniert_datei.pdf, retrieved February 26, 2017).

\section{References}

1 de Onis M, Blossner M, Borghi E: Global prevalence and trends of overweight and obesity among preschool children. American nutrition Clin Nutr 2010;92:1257-1264.

2 World Health Organization: Ending Childhood Obesity. Geneva, Word Health Organization, 2016.

3 Wabitsch M, Moss A, Kromeyer-Hauschild K: Unexpected plateauing of childhood obesity rates in developed countries. BMC Med 2014;12:17.

4 Caroli M, Vania A: Hysterie oder Ruf in die Wüste - Epidemiologie von Adipositas bei Kindern in Europa; in Ardelt-Gattinger E, Ring-Dimitriou S, Weghuber D (eds): Der gesunde Adipöse. Bern, Hans Huber, 2015, pp 23-30.

5 World Health Organization: Child Growth Standards: Methods and Development: Length/Height-for-Age, Weight-for-Age, Weight-for-Length, Weight-for-Height and Body Mass Index-for-Age. Geneva, World Health Organization, 2006.

6 Mayer M, Gleiss A, Hausler G, Borkenstein M, Kapelari K, Kostl G, Lassi M, Schemper M, Schmitt K, Blumel P: Weight and body mass index (BMI): current data for Austrian boys and girls aged 4 to under 19 years. Ann Hum Biol 2015;42:45-55.

7 Gardner DS, Hosking J, Metcalf BS, Jeffery AN, Voss LD, Wilkin TJ: Contribution of early weight gain to childhood overweight and metabolic health: a longitudinal study (EarlyBird 36). Pediatrics 2009;123:e67-73.

-8 Nader PR, O’Brien M, Houts R, Bradley R, Belsky J, Crosnoe R, Friedman S, Mei Z, Susman EJ; National Institute of Child Health, Human Development Early Child Care Research Network: Identifying risk for obesity in early childhood. Pediatrics 2006;118:e594-601.

-9 Swinburn B, Vandevijvere S: WHO report on ending childhood obesity echoes earlier recommendations. Public Health Nutri 2016;19:1-2.

10 Langford R, Bonell C, Jones H, Pouliou T, Murphy S, Waters E, Komro K, Gibbs L, Magnus D, Campbell R: The World Health Organization's Health Promoting Schools framework: a Cochrane systematic review and metaanalysis. BMC Public Health 2015;15:130.

11 Waters E, de Silva-Sanigorski A, Hall BJ, Brown T, Campbell KJ, Gao Y, Armstrong R, Prosser L, Summerbell CD: Interventions for preventing obesity in children. Cochrane Database Syst Rev 2011:CD001871.

12 Grillich L, Kien C, Takuya Y, Weber M, Gartlehner G: Effectiveness evaluation of a health promotion programme in primary schools: a cluster randomised controlled trial. BMC Public Health 2016;16:679.

13 Borys JM, Le Bodo Y, Jebb SA, Seidell JC, Summerbell C, Richard D, De Henauw S, Moreno LA, Romon M, Visscher TL, Raffin S, Swinburn B; EEN Study Group: EPODE approach for childhood obesity prevention: methods, progress and international development. Obes Rev 2012;13:299-315.

14 Romon M, Lommez A, Tafflet M, Basdevant A, Oppert JM, Bresson JL, Ducimetiere P, Charles MA, Borys JM: Downward trends in the prevalence of childhood overweight in the setting of 12-year school- and communitybased programmes. Public Health Nutr 2009;12:1735-1742.

15 Whelan J, Love P, Romanus A, Pettman T, Bolton K, Smith E, Gill T, Coveney J, Waters E, Allender S: A map of community-based obesity prevention initiatives in Australia following obesity funding 2009-2013. Aust N Z J Public Health 2015;39:168-171. 
Ring-Dimitriou et al.: SALTO - Study Protocol and Rationale of a Community-Oriented Obesity Prevention Program in the Kindergarten

-16 De Henauw S, Verbestel V, Marild S, Barba G, Bammann K, Eiben G, Hebestreit A, Iacoviello L, Gallois K, Konstabel K, Kovacs E, Lissner L, Maes L, Molnar D, Moreno LA, Reisch L, Siani A, Tornaritis M, Williams G, Ahrens W, De Bourdeaudhuij I, Pigeot I; IDEFICS Consortium: The IDEFICS community-oriented intervention programme: a new model for childhood obesity prevention in Europe? Int J Obes (Lond) 2011;35(suppl 1):S16-23.

17 Whelan J, Love P, Pettman T, Doyle J, Booth S, Smith E, Waters E: Cochrane update: predicting sustainability of intervention effects in public health evidence: identifying key elements to provide guidance. J Public Health (Oxf) 2014;36:347-351.

$>18$ Bayer O, von Kries R, Strauss A, Mitschek C, Toschke AM, Hose A, Koletzko BV: Short- and mid-term effects of a setting based prevention program to reduce obesity risk factors in children: a cluster-randomized trial. Clin Nutr 2009;28:122-128.

19 Koletzko B, Brands B, Demmelmair H: The Early Nutrition Programming Project (EARNEST): 5 y of successful multidisciplinary collaborative research. Am J Clin Nutr 2011;94:1749S-1753S.

20 Birnbaum J, Geyer C, Kirchberg F, Manios Y, Koletzko B, ToyBox-study G: Effects of a kindergarten-based, family-involved intervention on motor performance ability in 3- to 6-year-old children: the ToyBox-study. JSports Sci 2017;35:377-384.

21 Manios Y: The 'ToyBox-study' obesity prevention programme in early childhood: an introduction. Obes Rev 2012;13(suppl 1):1-2.

22 Hardy LL, King L, Kelly B, Farrell L, Howlett S: Munch and Move: evaluation of a preschool healthy eating and movement skill program. Int J Behav Nutr Phys Act 2010; 7:80.

-23 Payr A, Birnbaum J, Wildgruber A, Kreichauf S, Androutsos O, Lateva M, De Decker E, De Craemer M, Iotova V, Manios Y, Koletzko B; ToyBox-Study Group: Concepts and strategies on how to train and motivate teachers to implement a kindergarten-based, family-involved intervention to prevent obesity in early childhood. The ToyBox-study. Obes Rev 2014; 15(suppl 3):40-47.

24 Androutsos O, Apostolidou E, Iotova V, Socha P, Birnbaum J, Moreno L, De Bourdeaudhuij I, Koletzko B, Manios Y; ToyBox-Study Group: Process evaluation design and tools used in a kindergarten-based, family-involved intervention to prevent obesity in early childhood. The ToyBox-study. Obes Rev 2014;15(suppl 3):74-80.

-25 Pinket AS, De Craemer M, De Bourdeaudhuij I, Deforche B, Cardon G, Androutsos O, Koletzko B, Moreno LA, Socha P, Iotova V, Manios Y, Van Lippevelde W: Can parenting practices explain the differences in beverage intake according to socio-economic status: the Toybox-Study. Nutrients 2016;8:pii: E591.

-26 Sorensen K, Van den Broucke S, Fullam J, Doyle G, Pelikan J, Slonska Z, Brand H, Consortium Health Literacy Project E: Health literacy and public health: a systematic review and integration of definitions and models. BMC Public Health 2012;12:80.

-27 Reis RS, Salvo D, Ogilvie D, Lambert EV, Goenka S, Brownson RC; Lancet Physical Activity Series 2 Executive Committee: Scaling up physical activity interventions worldwide: stepping up to larger and smarter approaches to get people moving. Lancet 2016;388:1337-1348.

28 Haas S, Busch M, Kerschbaum J, Türscherl E, Weigl M: Health in All Policies am Beispiel der Kinder- und Jugendgesundheit. Vienna, GÖG/FGÖ, Gesundheit Österreich/Geschäftsbereich Fonds Gesundes Österreich, 2012, Wissen 9.

29 Bundesministerium für Gesundheit: Rahmen-Gesundheitsziele. Richtungsweisende Vorschläge für ein gesünderes Österreich. Langfassung. Vienna, Bundesministerium für Gesundheit, 2012.

30 Bundesministerium für Gesundheit, Lehner P, Sgarabottolo V, Zilberszac A: Nationaler Aktionsplan Ernährung. Vienna, Bundesministerium für Gesundheit, 2011.

31 Bundesministerium für Landesverteidigung und Sport: Nationaler Aktionsplan Bewegung. Vienna, Bundesministerium für Landesverteidigung und Sport, 2014.

32 Bundesministerium für Gesundheit, Wohlschlager V, Angel B: Kindergesundheitsstrategie. Vienna, Bundesministerium für Gesundheit, 2011.

33 Lobstein T, Frelut ML: Prevalence of overweight among children in Europe. Obes Rev 2003;4:195-200.

-34 Sallis JF, Cervero RB, Ascher W, Henderson KA, Kraft MK, Kerr J: An ecological approach to creating active living communities. Annu Rev Public Health 2006;27:297-322.

35 Dahlgren G, Whitehead M: Policies and Strategies to Promote Equity in Health. Copenhagen, World Health Organization, 1992.

36 Branca F, Nikogosian H, Lobstein T: The challenge of obesity in the WHO European Region and the strategies for response. Copenhagen, World Health Organization, 2007.

37 Newell KM: Motor skill acquisition. Annu Rev Psychol 1991;42:213-237.

38 Townsend A: Action Research. Maidenhead/Birkshire, McGraw-Hill, 2013.

39 Titze S, Ring-Dimitriou S, Schober PH, Halbwachs C, Samitz G, Miko HC, Lercher P, Stein KV, Gäbler C, Bauer R, Gollner E, Windhaber J, Bachl N, Dorner TE, Health Arbeitsgruppe Körperliche Aktivität/Bewegung/Sport der Österreichischen Gesellschaft für Public Health: Österreichische Empfehlungen für gesundheitswirksame Bewegung. Wien, Bundesministerium für Gesundheit, Gesundheit Österreich GmbH, Geschäftsbereich Fonds Gesundes Österreich, 2012, 8, pp 50.

40 Dür W, Griebler R: Die Gesundheit der österreichischen SchülerInnen im Lebenszusammenhang: Ergebnisse des WHO-HBSC-Survey 2006. Vienna, Bundesministerium für Gesundheit, Familie und Jugend, 2007.

41 Ring-Dimitriou S, Freudenthaler T, Aistleitner V, Weghuber D: Adipositas im Kindergarten vorbeugen - ein Projekt stellt sich vor. KiTa aktuell Österreich 2014;2:93-94. 
Ring-Dimitriou et al.: SALTO - Study Protocol and Rationale of a Community-Oriented Obesity Prevention Program in the Kindergarten

-42 DiClemente CC, Prochaska JO: Self-change and therapy change of smoking behavior: a comparison of processes of change in cessation and maintenance. Addict Behav 1982;7:133-142.

43 Fuchs R: Sport, Gesundheit und Public Health; in Strauß B, Schlicht W, Munzert J, Fuchs R (eds): Sportpsychologie, vol 1. Göttingen, Hogrefe, 2003.

44 Antonovsky A: Salutogenese. Zur Entmystifizierung der Gesundheit. Tübingen, Deutsche Gesellschaft für Verhaltenstherapie, 1997.

45 Rosenstock IM: What research in motivation suggests for public health. Am J Public Health Nations Health 1960;50:295-302.

46 Ajzen I: The theory of planned behaviour: reactions and reflections. Psychol Health 2011;26:1113-1127.

47 Newton AM: The Health beliefs of migrant farmworker parents: an ethnographic exploration. J Immigr Minor Health 2016;18:582-588.

48 Bandura A, Adams NE, Beyer J: Cognitive processes mediating behavioral change. J Pers Soc Psychol 1977;35: 125-139.

49 Ryan RM, Deci EL: Self-determination theory and the facilitation of intrinsic motivation, social development, and well-being. Am Psychol 2000;55:68-78.

50 Chatzisarantis NL, Hagger MS: Effects of an intervention based on self-determination theory on self-reported leisure-time physical activity participation. Psychol Health 2009;24:29-48.

51 World Health Organization: Monitoring, Evaluation and Review of National Health Strategies: A Country-Led Platform for Information and Accountability. Geneva, World Health Organization, 2011.

52 Czirkovits C, Winkler P: GBE als Grundlage für gesundheitspolitische Maßnahmen (Public Health Action Cycle). Vienna, Bundesgesundheitsagentur, 2009.

53 Craig P, Dieppe P, Macintyre S, Michie S, Nazareth I, Petticrew M: Developing and evaluating complex interventions: the new Medical Research Council guidance. Int J Nurs Stud 2013;50:587-592.

54 Mouratidou T, Miguel ML, Androutsos O, Manios Y, De Bourdeaudhuij I, Cardon G, Kulaga Z, Socha P, Galcheva S, Iotova V, Payr A, Koletzko B, Moreno LA; ToyBox-Study Group: Tools, harmonization and standardization procedures of the impact and outcome evaluation indices obtained during a kindergarten-based, familyinvolved intervention to prevent obesity in early childhood: the ToyBox-study. Obes Rev 2014;15(suppl 3):53-60.

55 Manios Y, Grammatikaki E, Androutsos O, Chinapaw MJ, Gibson EL, Buijs G, Iotova V, Socha P, Annemans L, Wildgruber A, Mouratidou T, Yngve A, Duvinage K, de Bourdeaudhuij I; ToyBox-study: A systematic approach for the development of a kindergarten-based intervention for the prevention of obesity in preschool age children: the ToyBox-study. Obes Rev 2012;13(suppl 1):3-12.

56 Baumann A, Nutbeam D: Evaluation in a Nutshell. A Practical Guide to the Evaluation of Health Promotion Programs. Melbourne, McGraw Hill, 2014.

57 Freudenthaler T, Ring-Dimitriou S: SALTO Manual - Evaluierung. Salzburg, Paris Lodron Universität Salzburg, 2015.

58 Freudenthaler T, Weghuber D, Trutschnig W, Ring-Dimitriou S: Measuring waist circumference in preschoolers. 26th European Childhood Obesity Group Congress. Thessaloniki, 2016.

59 Freudenthaler T, Ring-Dimitriou S: Die Erhebung der motorischen Kompetenz bei Vorschulkindern; in RingDimitriou S, Tilp M, Werner I (eds): Sportwissenschaft zwischen Bewegungsförderung und Trainingstherapie Herausforderungen und Perspektiven. Spectrum der Sportwissenschaften 2012 24(suppl):102-106.

60 Freudenthaler T, Ivad A, Paulmichl K, Weghuber D, Ring-Dimitriou S: Locomotor fitness in early childhood obesity. A pilot study of SALTO. Appetite 2015: DOI:10.1016/j.appet.2014.12.034.

-61 Freudenthaler T, Sommer N, Ardelt-Gattinger E, Blechert J, Weghuber D, Ring-Dimitriou S: A visual activity preference list for preschool (APL_4-6). Appetite 2015: DOI:10.1016/j.appet.2014.12.033.

-62 Sommer N, Meindl M, Blechert J, Freudenthaler T, Hattinger J, Weghuber D, Ring-Dimitriou S, Ardelt-Gattinger E: A visual nutrition preference list for preschool (NPL_4-6). Appetite 2015: DOI:10.1016/j.appet.2014.12.025.

63 Maislinger-Parzer M, Grössenberger M: Evaluation SALTO - Kindergartenpädagoginnen und Eltern. Hallein, Forschung Urstein/Urstein Research, 2016.

64 Hardy LL, King L, Farrell L, Macniven R, Howlett S: Fundamental movement skills among Australian preschool children. JSci Med Sport 2010;13:503-508.

65 Klimont J, Baldaszti E: Österreichische Gesundheitsbefragung 2014. Wien, STATISTIK AUSTRIA, 2015.

-66 De Henauw S, Huybrechts I, De Bourdeaudhuij I, Bammann K, Barba G, Lissner L, Marild S, Molnar D, Moreno LA, Pigeot I, Tornaritis M, Veidebaum T, Verbestel V, Ahrens W, IDEFICS Consortium: Effects of a communityoriented obesity prevention programme on indicators of body fatness in preschool and primary school children. Main results from the IDEFICS study. Obes Rev 2015;16(suppl 2):16-29.

-67 Manios Y, Androutsos O, Katsarou C, Iotova V, Socha P, Geyer C, Moreno L, Koletzko B, De Bourdeaudhuij I, ToyBox-Study Group: Designing and implementing a kindergarten-based, family-involved intervention to prevent obesity in early childhood: the ToyBox-study. Obes Rev 2014;15(suppl 3):5-13. 